\section{JURNAL EKONOMI EFEKTIF}

ISSN : $2622-8882$, E-ISSN : 2622-9935

Jurnal Ekonomi Efektif, Vol. 4, No. 2, Januari 2022

@Prodi Manajemen Fakultas Ekonomi

Universitas Pamulang

\title{
PENGARUH KOMUNIKASI TERHADAP KINERJA KARYAWAN PADA PT BINA AGRA MULYA DI JAKARTA
}

\author{
Bralius Gideon Siahaan ${ }^{1}$, Imas Masriah ${ }^{2 *}$ \\ Universitas Pamulang, Tangerang Selatan, Banten, Indonesia \\ siahaan.gideons@gmail.com ${ }^{1}, \underline{\text { dosen02036@unpam.ac.id }{ }^{2 *}}$
}

Manuskrip: Oktober -2021; Ditinjau: November: -2021; Diterima: November-2021; Online: Januari -2022; Diterbitkan: Januari-2022

\begin{abstract}
ABSTRAK
Penelitian ini bertujuan untuk mengetahui pengaruh komunikasi terhadap kinerja karyawan pada PT. PT. Bina Agra Mulya di Jakarta. Metode yang digunakan adalah explanatory research dengan sampel sebanyak 50 responden. Teknik analisis menggunakan analisis statistik dengan pengujian regresi, korelasi, determinasi dan uji hipotesis. Hasil penelitian ini variabel komunikasi diperoleh nilai rata-rata skor sebesar 3,312 dengan kriteria baik. Variabel kinerja karyawan diperoleh nilai rata-rata skor sebesar 3,776 dengan kriteria baik. Komunikasi berpengaruh positif dan signifikan terhadap kinerja karyawan dengan nilai persamaan regresi $\mathrm{Y}=9,917+0,841 \mathrm{X}$, dan nilai koefisien korelasi 0,667 atau memiliki tingkat hubungan yang kuat dengan nilai determinasi 44,5\%. Uji hipotesis diperoleh signifikansi 0,000 $<0,05$.
\end{abstract}

Kata Kunci: Komunikasi, Kinerja Karyawan

\begin{abstract}
This study aims to determine the effect of communication on employee performance at PT. PT. Bina Agra Mulya in Jakarta. The method used is explanatory research with a sample of 50 respondents. The analysis technique uses statistical analysis with regression, correlation, determination and hypothesis testing. The results of this study of communication variables obtained an average score of 3,312 with good criteria. Employee performance variable obtained an average score of 3.776 with good criteria. Communication has a positive and significant effect on employee performance with the value of the regression equation $Y=9.917$ $+0.841 X$, and the correlation coefficient value of 0.667 or has a strong relationship level with a determination value of $44.5 \%$. Hypothesis testing obtained a significance of $0.000<0.05$.
\end{abstract}

Keywords: Communication, Employee Performance 


\section{PENDAHULUAN}

\section{A. Latar Belakang}

Apapun fase kehidupan karyawan, komunikasi tetap menjadi bagian yang utama. Manusia dirancang sebagai makhluk sosial, artinya mereka tidak dapat hidup tanpa orang lain. Saat bekerja, komunikasi tetap dibutuhkan agar pekerjaan semakin lancar dan tujuan dapat tercapai.

Komunikasi dalam perusahaan dapat diibaratkan seperti makanan bagi tubuh, yaitu merupakan hal yang paling penting dalam melakukan pekerjaan. Sebagai karyawan, mereka membutuhkan komunikasi agar dapat menyelesaikan pekerjaan yang telah disepakati. Selain itu, komunikasi juga dapat menghilangkan prasangka dan asumsi tidak benar antara karyawan, sehingga menciptakan lingkungan kerja yang sehat.

Dari penjelasan di atas, sudah jelas karyawan dapat bekerja sama mencapai tujuan perusahaan berkat adanya komunikasi. Selain itu, kinerja karyawan juga semakin baik apabila perusahaan menerapkan komunikasi korporat yang benar. Adanya komunikasi membuat anggota suatu tim atau perusahaan bebas mengutarakan pendapatnya. Tidak hanya itu, mereka juga dapat berpartisipasi dalam pembuatan keputusan yang krusial untuk kemajuan bisnis. Komunikasi juga dapat membuat karyawan menjadi pendengar yang aktif. Mereka dapat merespons apa yang sedang dibicarakan oleh atasan dan mampu memberikan feedback terhadap kebijakan perusahaan.

Komunikasi dan keterbukaan inilah yang dapat membangun manajemen kerja menjadi lebih baik. Tentunya, kinerja karyawan semakin meningkat apabila manajemennya juga baik. Saat bekerja, pastinya karyawan tidak dapat menyelesaikan semua pekerjaannya sendiri. Karyawan membutuhkan tim supaya tujuan dapat tercapai. Agar kerja sama tim meningkat, dibutuhkan komunikasi antar anggota.

Adanya komunikasi membuat kerja sama tim semakin mudah. Di tengah persaingan bisnis yang semakin kompetitif, kerja sama tim yang solid dan kuat semakin dibutuhkan agar perusahaan dapat bergerak lebih maju. Kerja sama tim ini mengajak anggotanya agar mereka berani bertanggung jawab dan mengerjakan bagian mereka secara optimal.

Komunikasi dan kerja sama tim ini juga menghasilkan efisiensi, sehingga kinerja karyawan pun semakin meningkat. Ingat, salah satu faktor yang membangun kinerja karyawan adalah jelasnya pembagian tugas di dalamnya.

Setiap perusahaan pastilah memiliki karyawan dengan karakteristik yang unik antar individu, alias mereka mempunyai perbedaan latar belakang. Menariknya, mereka semua harus bekerja sama untuk mencapai tujuan perusahaan yang sudah ditentukan. Karena itu, mekanisme feedback atau masukan sangat dibutuhkan, dan komunikasi adalah faktor utama yang membentuknya. Adanya mekanisme feedback membuat seorang manajer dapat memantau hasil kerja karyawannya. Hasil kerja yang nantinya disampaikan kepada karyawannya ini berujung pada perbaikan kinerja karyawan sehingga lebih baik lagi di masa depan.

Dengan komunikasi yang efektif akan mampu meningkatkan moral karyawan agar sesuai dengan nilai-nilai perusahaan. Setiap perusahaan punya nilai dan visinya sendiri, sehingga cara kerja karyawan pun harus menyesuaikan dengan nilai-nilai yang sudah dibangun. Hasilnya, tercipta lingkungan kerja yang mendukung dan pasti mengurangi tingkat stres karyawan. Komunikasi ini dapat menciptakan lingkungan kerja yang sehat, karena karyawan berhak mengutarakan pendapat serta keluh kesahnya. Solusinya dapat dicari sehingga permasalahan dapat segera selesai dan karyawan dapat meningkatkan kinerjanya. 
Keterlibatan karyawan juga berpengaruh pada kinerja perusahaan yang lahir dari komunikasi. Karyawan yang tahu bagaimana menyelesaikan tugasnya biasanya memiliki kemampuan komunikasi yang baik sehingga produktivitasnya semakin meningkat. Lebih baik lagi, karyawan juga dapat saling memberikan ide dan pengetahuan yang pastinya berguna untuk kemajuan anggota tim lainnya. Hal-hal baru yang mereka dapatkan pasti dapat mendorong kinerja mereka agar semangat lagi.

Berasarkan pemaparan di atas, maka penulis tertarik melakukan penelitian dengan judul "Pengaruh Komunikasi Terhadap Kinerja Karyawan Pada PT. PT. Bina Agra Mulya di Jakarta".

\section{B. Rumusan Masalah}

1. Bagaimana komunikasi pada PT. PT. Bina Agra Mulya di Jakarta ?.

2. Bagaimana kinerja karyawan pada PT. PT. Bina Agra Mulya di Jakarta ?.

3. Adakah pengaruh antara komunikasi terhadap kinerja karyawan pada PT. PT. Bina Agra Mulya di Jakarta?.

\section{Tujuan Penelitian}

1. Untuk mengetahui kondisi komunikasi pada PT. PT. Bina Agra Mulya di Jakarta.

2. Untuk mengetahui kondisi kinerja karyawan pada PT. PT. Bina Agra Mulya di Jakarta.

3. Untuk mengetahui pengaruh komunikasi terhadap kinerja karyawan pada PT. PT. Bina Agra Mulya di Jakarta.

\section{TINJAUAN PUSTAKA}

\section{Komunikasi}

Menurut Hutapea dan Nuriana (2020:28) komunikasi diartikan sebagai proses pemindahan, pengertian dalam bentuk gagasan atau komunikasi dari seseorang ke orang lain. Perpindahan pengertian tersebut melibatkan lebih dari sekedar kata-kata yang di gunakan dalam percakapan, tetapi juga ekspresi wajah, intonasi, titik putus voka dan sebagainya.

\section{Kinerja Karyawan}

Menurut Mangkunegara (2019:75) pengertian kinerja adalah hasil kerja secara kualitas dan kuantitas yang dicapai oleh seorang pegawai dalam melaksanakan tugasnya sesuai dengan tanggung jawab yang diberikan kepadanya. Adapun indikator yang digunakan sebagai berikut:

\section{III.METODE PENELITIAN}

\section{Populasi}

Yang dijadikan sebagai populasi dalam penelitian ini adalah responden yang berjumlah 50 responden PT. PT. Bina Agra Mulya di Jakarta

\section{Sampel}

Teknik pengambilan sampling dalam penelitian ini adalah sampel jenuh, dimana semua anggota populasi dijadikan sebagai sampel. Dengan demikian sampel dalam penelitian ini sampel yang digunakan berjumlah 50 responden.

\section{Jenis Penelitian}

Jenis penelitian yang dipakai adalah asosiatif, dimana tujuannya adalah untuk mengetahui atau mencari keterhubungan antara variabel independen terhadap variabel dependennya 


\section{Metode Analisis Data}

Dalam menganalisis data digunakan uji validitas, uji reliabilitas, analisis regresi linier sederhana, analisis koefisien korelasi, analisis koefisien determinasi dan pengujian hipotesis.

\section{IV.HASIL PENELITIAN}

\section{Analisis Deskriptif}

Pada pengujian ini digunakan untuk mengetahui skor minimum dan maksimum skor tertinggi, ratting score dan standar deviasi dari masing-masing variabel. Adapun hasilnya sebagai berikut:

Tabel 1. Hasil Analisis Descriptive Statistics

Descriptive Statistics

\begin{tabular}{lr|r|r|r|r} 
& N & Minimum & Maximum & Mean & Std. Deviation \\
\hline Komunikasi (X) & 50 & 29 & 41 & 33.12 & 3.354 \\
\hline Kinerja Karyawan (Y) & 50 & 29 & 48 & 37.76 & 4.226 \\
\hline Valid N (listwise) & 50 & & & & \\
\hline
\end{tabular}

Komunikasi diperoleh varians minimum sebesar 29 dan varians maximum 41 dengan ratting score sebesar 3,312 dengan standar deviasi 3,354. Skor ini termasuk pada rentang sakala 3,40 - 4,19 dengan kriteria baik atau setuju. Kinerja karyawan diperoleh varians minimum sebesar 29 dan varians maximum 48 dengan ratting score sebesar 3,776 dengan standar deviasi 4,226. Skor ini termasuk pada rentang sakala 3,40 - 4,19 dengan kriteria baik atau setuju.

\section{Analisis Kuantitatif}

Pada analisis ini dimaksudkan untuk mengetahui pengaruh variabel independen terhadap variabel dependen. Adapun hasil pengujian sebagai berikut:

\section{a. Analisis Regresi Linier Sederhana}

Uji regresi ini dimaksudkan untuk mengetahui perubahan variabel dependen jika variabel independen mengalami perubahan. Adapun hasil pengujiannya sebagai berikut:

\begin{tabular}{|c|c|c|c|c|c|}
\hline \multirow[b]{2}{*}{ Model } & \multicolumn{2}{|c|}{$\begin{array}{l}\text { Unstandardized } \\
\text { Coefficients }\end{array}$} & \multirow{2}{*}{$\begin{array}{c}\text { Standardized } \\
\text { Coefficients } \\
\text { Beta }\end{array}$} & \multirow[b]{2}{*}{$\mathrm{t}$} & \multirow[b]{2}{*}{ Sig. } \\
\hline & $\mathrm{B}$ & Std. Error & & & \\
\hline $\begin{array}{ll}1 & \text { (Constant) }\end{array}$ & 9.917 & 4.509 & & 2.200 & .033 \\
\hline Komunikasi (X) & .841 & .135 & .667 & 6.206 & .000 \\
\hline
\end{tabular}

a. Dependent Variable: Kinerja Karyawan (Y)

Berdasarkan hasil pengujian pada tabel di atas, diperoleh persamaan regresi $\mathrm{Y}$ $=9,917+0,841 \mathrm{X}$. Dari persamaan tersebut dijelaskan sebagai berikut:

1) Konstanta sebesar 9,917 diartikan jika komunikasi tidak ada, maka telah terdapat nilai kinerja karyawan sebesar 9,917 point.

2) Koefisien regresi komunikasi sebesar 0,841 , angka ini positif artinya setiap ada peningkatan komunikasi sebesar 0,841 point maka kinerja karyawan juga akan mengalami peningkatan sebesar 0,841 point.

\section{b. Analisis Koefisien Korelasi}

Analisis koefisien korelasi dimaksudkan untuk mengetahui tingkat kekuatan hubungan dari variabel independen terhadap variabel dependen. Adapun hasil pengujian sebagai berikut: 
Tabel 3. Hasil Pengujian Koefisien Korelasi Komunikasi Terhadap Kinerja Karyawan.

Correlations $^{\mathbf{b}}$

\begin{tabular}{llr|r} 
& & $\begin{array}{c}\text { Komunikasi } \\
(\mathrm{X})\end{array}$ & \multicolumn{2}{|c}{$\begin{array}{r}\text { Kinerja Karyawan } \\
(\mathrm{Y})\end{array}$} \\
\hline Komunikasi (X) & Pearson Correlation & 1 & $.667^{* * *}$ \\
\cline { 2 - 4 } & Sig. (2-tailed) & & .000 \\
\hline Kinerja Karyawan (Y) & Pearson Correlation & $.667^{* *}$ & 1 \\
\cline { 2 - 4 } & Sig. (2-tailed) & .000 & \\
\hline
\end{tabular}

**. Correlation is significant at the 0.01 level (2-tailed).

b. Listwise $\mathrm{N}=50$

Berdasarkan hasil pengujian diperoleh nilai korelasi sebesar 0,667 artinya komunikasi memiliki hubungan yang kuat terhadap kinerja karyawan.

\section{c. Analisis Koefisien Determinasi}

Analisis koefisien determinasi dimaksudkan untuk mengetahui besarnya persentase pengaruh dari variabel independen terhadap variabel dependen. Adapun hasil pengujian sebagai berikut:

Tabel 4. Hasil Pengujian Koefisien Determinasi Komunikasi Terhadap Kinerja

Karyawan.

\section{Model Summary}

\begin{tabular}{|c|c|c|c|c|}
\hline \multicolumn{5}{|c|}{$\mathbf{M}$} \\
\hline Model & $\mathrm{R}$ & R Square & $\begin{array}{l}\text { Adjusted R } \\
\text { Square }\end{array}$ & $\begin{array}{l}\text { Std. Error of the } \\
\text { Estimate }\end{array}$ \\
\hline 1 & $.667^{\mathrm{a}}$ & .445 & .434 & 3.180 \\
\hline
\end{tabular}

a. Predictors: (Constant), Komunikasi (X)

Berdasarkan hasil pengujian diperoleh nilai determinasi sebesar 0,445 artinya komunikasi memiliki kontribusi pengaruh sebesar 44,5\% terhadap kinerja karyawan, sedangkan sisanya sebesar 55,5\% dipengaruhi oleh faktor lain yang tidak dilakukan penelitian.

\section{d. Uji Hipotesis}

Pengujian hipotesis dengan uji t digunakan untuk mengetahui hipotesis mana yang diterima.

Rumusan hipotesis: Terdapat pengaruh yang signifikan komunikasi terhadap kinerja karyawan.

Tabel 5. Hasil Uji Hipotesis Komunikasi Terhadap Kinerja Karyawan.

\section{Coefficients $^{\mathrm{a}}$}

Unstandardized

Coefficients

\begin{tabular}{|c|c|c|c|c|c|}
\hline \multirow[b]{2}{*}{ Model } & \multicolumn{2}{|c|}{ Coenincients } & \multirow{2}{*}{ Beta } & \multirow[b]{2}{*}{$\mathrm{t}$} & \multirow[b]{2}{*}{ Sig. } \\
\hline & $\mathrm{B}$ & Std. Error & & & \\
\hline $1 \quad$ (Constant) & 9.917 & 4.509 & & 2.200 & .033 \\
\hline Komunikasi (X) & .841 & .135 & .667 & 6.206 & .000 \\
\hline
\end{tabular}

a. Dependent Variable: Kinerja Karyawan (Y)

Berdasarkan hasil pengujian pada tabel di atas, diperoleh nilai t hitung $>\mathrm{t}$ tabel atau $(6,206>2,011)$, dengan demikian hipotesis yang diajukan bahwa terdapat pengaruh yang signifikan atara komunikasi terhadap kinerja karyawan diterima.

\section{Pembahasan Hasil Penelitian}

\section{Kondisi Jawaban Responden Variabel Komunikasi}

Berdasarkan jawaban responden, variabel komunikasi diperoleh ratting score sebesar 3,312 berada di rentang skala 3,40-4,19 dengan kriteria baik atau setuju. 


\section{Kondisi Jawaban Responden Variabel Kinerja Karyawan}

Berdasarkan jawaban responden, variabel kinerja karyawan diperoleh ratting score sebesar 3,776 berada di rentang skala 3,40 - 4,19 dengan kriteria baik atau setuju.

\section{Pengaruh Komunikasi Terhadap Kinerja Karyawan}

Komunikasi berpengaruh signifikan terhadap kinerja karyawan dengan persamaan regresi $\mathrm{Y}=9,917+0,841 \mathrm{X}$, nilai korelasi sebesar 0,667 atau memiliki hubungan yang kuat dengan kontribusi pengaruh sebesar $44,5 \%$. Pengujian hipotesis diperoleh nilai $t$ hitung $>t$ tabel atau $(6,206>2,011)$. Dengan demikian hipotesis yang diajukan bahwa terdapat berpengaruh signifikan antara komunikasi terhadap kinerja karyawan diterima.

\section{KESIMPULAN DAN SARAN}

\section{Kesimpulan}

a. Variabel komunikasi diperoleh ratting score sebesar 3,312 berada di rentang skala 3,40 - 4,19 dengan kriteria baik atau setuju.

b. Variabel kinerja karyawan diperoleh ratting score sebesar 3,776 berada di rentang skala 3,40 - 4,19 dengan kriteria baik atau setuju.

c. Komunikasi berpengaruh signifikan terhadap kinerja karyawan dengan persamaan regresi $\mathrm{Y}=9,917+0,841 \mathrm{X}$, nilai korelasi sebesar 0,667 atau kuat dan kontribusi pengaruh sebesar $44,5 \%$ sedangkan sisanya sebesar $55,5 \%$ dipengaruhi faktor lain. Uji hipotesis diperoleh nilai $t$ hitung $>\mathrm{t}$ tabel atau $(6,206>2,011)$.

\section{Saran}

a. Untuk berkinerja secara efektif, kelompok perlu menjaga beberapa control atas anggota, merangsang anggota untuk melakukan, memberi kesempatan

b. Kinerja perusahaan dapat ditingkatkan dengan memberdayakan karyawan dengan menegakkan peraturan yang baik dan pemberian motivasi yang lebih inten lagi.

\section{DAFTAR PUSTAKA}

Abdullah. M (2014). Manajemen dan Evaluasi Kinerja Karyawan. Yogyakarta: Penerbit Aswaja Pressindo.

Algifari. (2015). Analisis Regresi untuk Bisnis dan Ekonomi. Yogyakarta: BPFE.

Arikunto, Suharsimi (2014). Prosedur Penelitian Suatu Pendekatan Praktek. Jakarta: Rineka Cipta.

Bangun, Wilson. (2012). Manajemen Sumber Daya Manusia. Jakarta: Erlangga

Bejo Siswanto (2013) Manajemen Tenaga Kerja Rancangan dalam Pendayagunaan dan Pengembangan Unsur Tenaga Kerja. Bandung: Sinar Baru.

Dessler, G. (2006.). Manajemen Sumber Daya Manusia. Jilid II. Jakarta: Indeks.

Edi Sutrisno (2016). Manajemen Sumber Daya Manusia. Jakarta: Prenadamedia Group.

Edi Sutrisno (2016). Manajemen Sumber Daya Manusia. Jakarta: Prenadamedia Group.

George Terry R \& Rue, Leslie W. Rue (2016). Dasar-Dasar Manajemen. Jakarta Bumi Aksara.

Gerry Dessler (2016). Human Resources Management. Prenticehall. London: International Inc.

Handoko (2016). Manajemen Personalia dan Sumberdaya Manusia. Yogyakarta: BPFE.

Hasibuan, Malayu S.P. (2016). Manajemen Sumber Daya Manusia. Edisi Revisi. Jakarta: PT Bumi Aksara. 
Imam Ghozali (2017). "Aplikasi Analisis Multivariate Dengan Program SPSS”. Edisi Kelima. Semarang: Badan Penerbit Undip.

Istijanto (2014) "Riset Sumber Daya Manusia". Jakarta: PT. Gramedia Pustaka

Kharis, Ismu Fadli (2011). Studi Mengenai Impulse Buying dalam Penjualan Online. Semarang : Skripsi Universitas Diponegoro

Luthans Fred (2014). Organizational Behavior. Ney York: McGraw-Hill. New York.

Mangkunegara, Prabu Anwar. (2016). Evaluasi Kinerja SDM. Cetakan ke tujuh, PT Refika Aditama: Bandung.

Rao, Purba, (2012). Measuring Consumer Perceptions Through Factor Analysis. The Asian.

Robbins, P.S, \& Judge, A.T. (2003). Organizational Behavior. Jakarta: Salemba Empat.

Santoso, Singgih (2015). Menguasai Statistik Multivariat. Jakarta: PT Elex Media Komputindo.

Sedarmayanti (2016) Manajemen Sumber Daya Manusia, Reformasi Birokrasi dan Manajemen Karyawan Negeri Sipil, Cetakan Kelima, Bandung: PT Refika Aditama.

Sudjana (2014). Metode Statistika. Bandung: Tarsido.

Sugiyono (2017). Metode Penelitian Administrasi dilengkapi dengan Metode R \& D. Bandung: Alfabeta.

Veithzal Rivai (2015) Manajemen Sumber Daya Manusia Untuk Perusahaan. Jakarta: Raja Grafindo Persada.

Wibowo (2015). Manajemen Kinerja. Jakarta: PT. Raja Grafindo Persada. 